\title{
Study on toughness and toughening mechanism of cement-based fiber materials
}

\author{
$H u$ Huixiao $^{1 *}$, LiQiang $^{1}$, Cao $\mathrm{Lu}^{1}$ \\ ${ }^{1}$ School of Port and Transportation Engineering,Zhejiang Ocean University,Zhoushan 316000
}

\begin{abstract}
In order to improve the character of common cement mortar which are brittle and easily cracked, and to take advantage of the local materials, abandoned fishing nets was used toform get the cement-based fiber materials. In this study, the influence of the amount and length of abandoned fishing nets on the mechanical properties of cement mortar and its mechanism were discussed. Four different lengths of abandoned fishing nets were adopted under four kinds of dosages to mix with mortar and make a total of 16 test blocks. Then the flexural strengths of the prepared test blocks were tested, and the load-deflection curve of the test block was obtained. The results show that the residual strength after the test block after which reaches the peak load in the flexural test generally increases with the increase of the fiber content and the length of the fiber, but when the dosage and length increase to a certain range, the influences becomecomplicated. The crack propagation simulation byAbaqus further revealed the reinforcement mechanism, and it can be concluded that the bridging between the fiber and the matrix has a great influence on the character toughness.
\end{abstract}

\section{Introduction}

As the main construction engineering material, mortar has some character defects during construction, such as brittleness, low tensile strength, large dry shrinkage and poor impact resistance. These defects make the mortar products susceptible to cracks and reduce the durability of the building. Adding fiber is a good way to improve the toughness of the mortar product and it has been reported that polypropylene fiber can effect the mechanical properties of cement-based materials ${ }^{[1-2]}$. To obtain better building materials, many researchers have studied the cement-based fiber toughening materials ${ }^{[3-4]}$ and some have been applied to practical projects in the United States and Japan ${ }^{[5,6]}$.

Fiber reinforced cement-based composite material is a composite material composed of cement paste, mortar or cement concrete as the substrate, and a combination of non-continuous short fibers or continuous long fibers as reinforcing materials ${ }^{[7]}$. The fiber can prevent the expansion of micro-cracks in the cement matrix and the tensile load across the crack, which can improve the composite tensile strength, flexural strength and fracture energy of the materials significantly compared to the common cement.

In this study, we combined the local available material, abandoned fishing net wires, to make the cement-based fiber toughened materials, and used the bending test and the method of numerical simulation to study the property of this kind of materials and the mechanism of reinforcement and toughening. Then the influence of the length, content of the fiber under different ages to the fiber and cement matrix was discussed and the efficiency of adding fiber was evaluated by the factor of destruction.

\section{Test materials and test methods}

\subsection{Experiment material}

The curing agent used in the test was Conch brand No. 425 ordinary Portland cement, and the new standard (ISO) sand was used in the cement test. The mass ratio of themortar is made by the ratio of cement: standard sand:

*Corresponding author: Hu Huixiao huhuixiao0322@163.com 
water $=1: 3: 0.5$. One pot of mortar can make three test pieces. The required amount of each pot material is as follows: cement $(450 \pm 2) \mathrm{g}$, standard sand $(1350 \pm 5) \mathrm{g}$, water $(225 \pm 1) \mathrm{mL}$. The reinforced material is made of discarded fishing net wire (polyethylene fiber) as shown in Figure 1. It was added in an amount of $0.1 \%, 0.15 \%$, $0.2 \%$, and $0.25 \%$ by mass in four different fiber lengths.

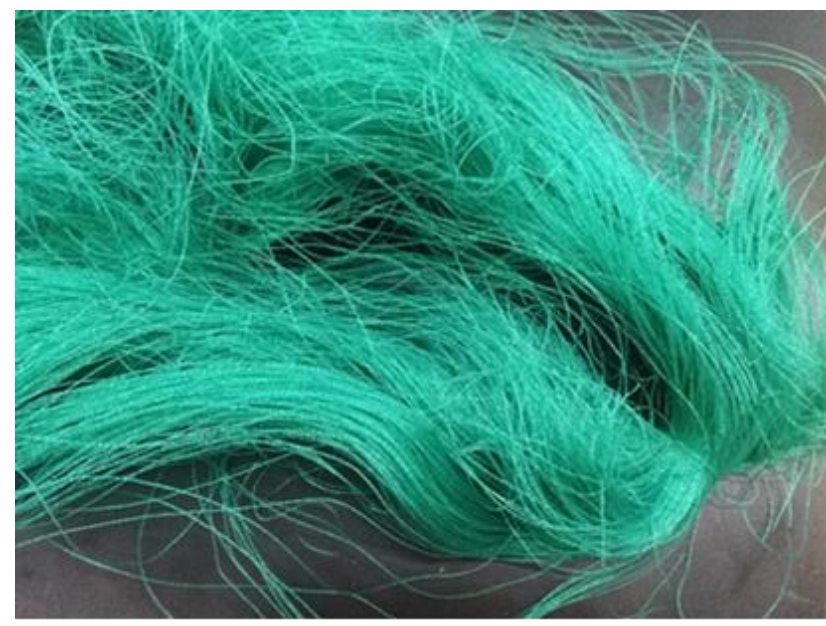

Fig.1 Abandoned fishing net line

\subsection{Test equipment}

The test equipment includes automatic cement load bending and compression testing machine, cement concrete constant temperature and humidity standard curing room (STYH-80,Zhejiang Geotechnical Instrument Manufacturing Co., Ltd.), cement mortar mixer, split hydraulic jack 10T, ZNLBS micro S type Tension sensor (range 10N), ZT-96 cement mortar vibrating table, cement scraper, lubricating oil, electronic scale, scale, beaker $(500 \mathrm{ml})$, scissors, mold, displacement meter, magnetic table and other accessories.

\subsection{Test methods}

\subsubsection{Preparation of mortar}

Under different fiber lengths, the fiber content is $2.03 \mathrm{~g}$, $3.04 \mathrm{~g}, 4.05 \mathrm{~g}$, and $5.06 \mathrm{~g}$, respectively. The water, cement and standard sand was weighted with a balance under the accuracy of $\pm 1 \mathrm{~g}$. The accuracy of the balance used for weighing discarded fishing nets was $\pm 0.01 \mathrm{~g}$. Automatic dropper plus $225 \mathrm{~mL}$ water with the accuracy of $1 \mathrm{~mL}$. Each pot of mortar is mechanically agitated using a mixer with the following procedure: Pour the standard sand into the sand tank on the upper part of the mixer, then add the water to the mixing pot, then add the cement, and place the pot on the holder and raise it to a fixed position. Press the start button and the machine will automatically stir at a low speed for 30 s, automatically add standard sand at the same time as the second 30s, then enter the third $30 \mathrm{~s}$ at a high speed stirring. In the first $15 \mathrm{~s}$ of the static stop for $90 \mathrm{~s}$, the mortar on the blade and the wall of the pot was scraped into the middle of the pot with a rubber scraper, then stirred at high speed for $60 \mathrm{~s}$. For each mixing phase, the time error should be within $\pm 1 \mathrm{~s}$.

\subsubsection{Test block preparation}

The mortar was formed immediately after preparation. The oil-coated test piece was fixed on the forming vibration table. The stirred mortar was placed in two layers into the test mold using a suitable spoon. In the first layer, approximately $300 \mathrm{~g}$ of mortar was placed in each tank. The large broadcaster is vertically placed on the top of the mold sleeve, and the material layer is leveled back and forth along each mold cavity, and then the vibrating table was automatically activated 60 times. After being installed, the second layer of mortar was also leveled with a small spreader and shaken again for 60 times. Then, the test pattern was moved to the console. A metal scraper is placed at one end of the top of the test pattern with an angle of nearly 90 degrees. The metal scraper moved slowly to the other end by the direction of the length of the test pattern by the lateral sawing action, scraped off the mortar exceeding the test portion, and smoothed the surface of the test piece with the same scraper at a nearly horizontal level. The test pattern was marked or added a note to indicate the test block number. The prepared sample was placed in a standard curing box, and the size of the sample was $40 \mathrm{~mm} * 40 \mathrm{~mm} * 160 \mathrm{~mm}$, and the curing period was 3 days, 7 days, and 28 days, respectively.

\subsubsection{Bending test}

The equipment of the flexural test is shown in Figure 2. At the beginning of the test, the sample was placed on a fully automatic cement load compression and compression tester, and two displacement meters were 
fixed on both sides of the sample with a magnetic table. Then the sample was load slowly with a split hydraulic jack until the $8 \mathrm{~mm}$ trip of the jack is completed. The force of the pressure sensor and the displacement of the displacement gauge during the test were recorded.

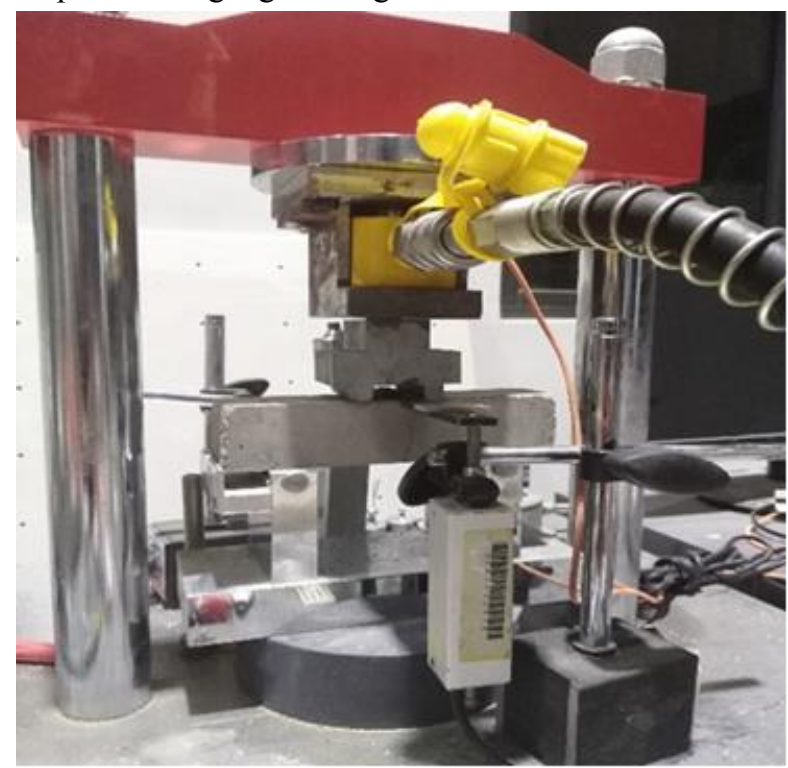

Fig.2 Folding test schematic

\section{Results}

\subsection{The influence of fiber lengths}

After the test block was prepared well, the flexural test was carried out by a fully automatic cement load compression and compression tester. During the test, the split hydraulic jack was manually loaded slowly, and the force of the pressure sensor and the displacement of the displacement gauge during the test were recorded. The specific sample size and the number of effective load deflection curve groups were shown in Table 1.

Table.1. The number of production test pieces and the number of load and deflection curves of each group of flexural test pieces

\begin{tabular}{|c|c|c|c|c|c|c|c|c|c|c|c|c|c|c|}
\hline & \multicolumn{4}{|c|}{$3 d$} & \multicolumn{6}{|c|}{$7 d$} & \multicolumn{4}{|c|}{$28 \mathrm{~d}$} \\
\hline & & $15 \mathrm{~mm}$ & $20 \mathrm{~mm}$ & $25 \mathrm{~mm}$ & $10 \mathrm{~mm}$ & & $15 \mathrm{~mm}$ & $20 \mathrm{~mm}$ & $25 \mathrm{~mm}$ & & $10 \mathrm{~mm}$ & $15 \mathrm{~mm}$ & $20 \mathrm{~mm}$ & $25 \mathrm{~mm}$ \\
\hline $0.1 \%$ & 3 & & 3 & 3 & $0.1 \%$ & 3 & 3 & 3 & 3 & $0.1 \%$ & 3 & 3 & 3 & 3 \\
\hline $0.15 \%$ & 3 & & 3 & 3 & $0.15 \%$ & 3 & 3 & 3 & 3 & $0.15 \%$ & 3 & 3 & 3 & 3 \\
\hline $0.2 \%$ & 3 & & 3 & 3 & $0.2 \%$ & 3 & 3 & 3 & 3 & $0.2 \%$ & 3 & 3 & 3 & 3 \\
\hline $0.25 \%$ & 3 & & 3 & 3 & $0.25 \%$ & 3 & 3 & 3 & 3 & $0.25 \%$ & 3 & 3 & 3 & 3 \\
\hline
\end{tabular}

The load-deflection relationship of test pieces with different fiber lengths of 28 days is shown in Fig. 3.

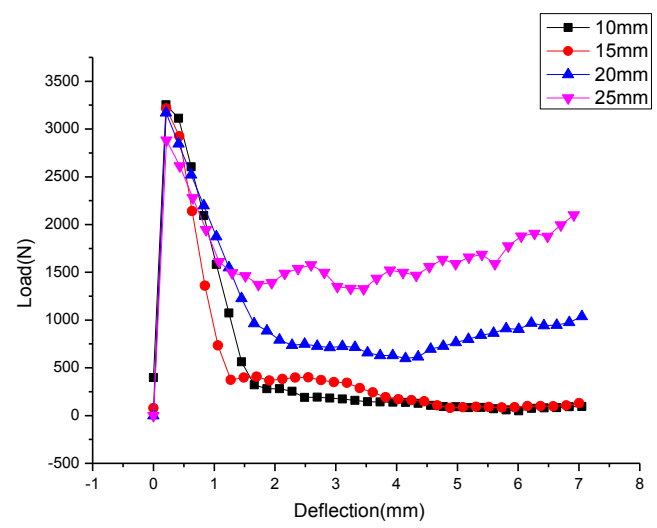

3-1（28d-0.1\%）

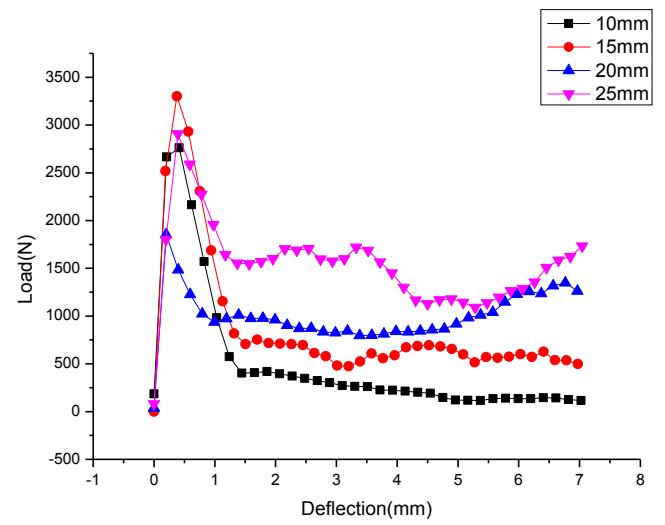

$3-2(28 \mathrm{~d}-0.15 \%)$ 


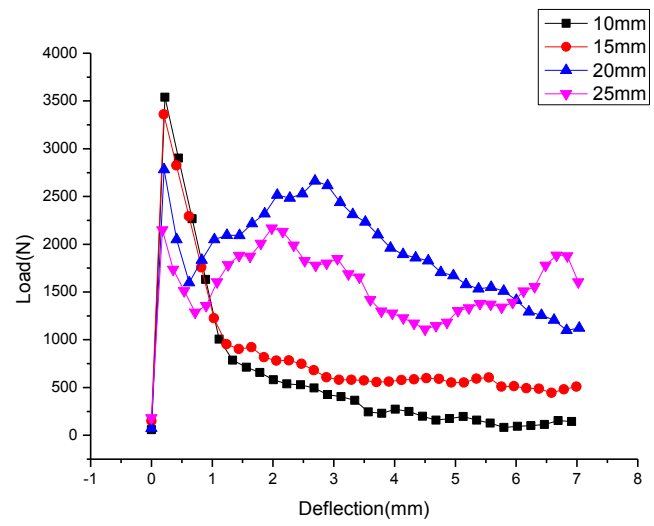

$3-3(28 \mathrm{~d}-0.2 \%)$

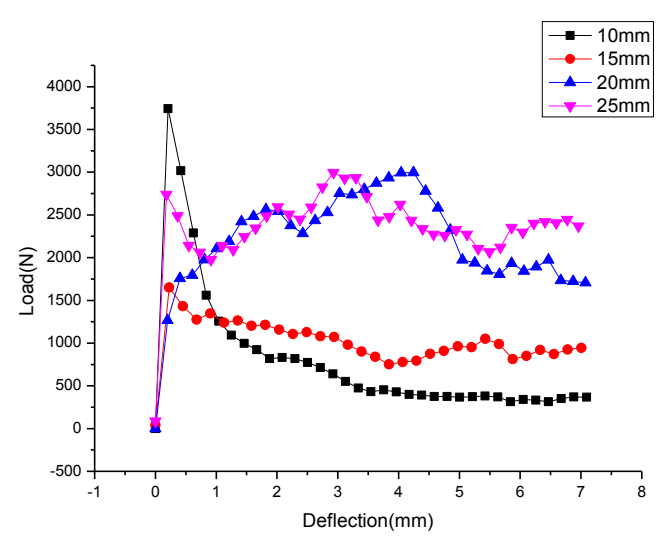

\section{$3-3(28 d-0.25 \%)$}

Fig. 3. The load and deflection curves of different fiber length It can be seen in Figure 3 that the load and deflection curves differed with the fiber lengths under the same age and the same fiber content. and it has the following regulations:

(1) When the fiber length is $10 \mathrm{~mm}$ and $15 \mathrm{~mm}$, the curve tends to be about the same, but a test piece incorporating a fiber of $15 \mathrm{~mm}$ provides greater residual strength. So the longer fiber length has a larger residual strength and a better toughening effect on the cement-based material.

(2) When the blending amount is low and the fiber length is $25 \mathrm{~mm}$, the load area under the peak and the deflection curve are larger, and the flexural toughness after peak is better. However, in the case of a high amount of blending, when the length of the incorporated fiber is also large, the toughness property of the test piece has little influence by the fiber length.

As reviewed, the toughness properties of cement-based fiber toughened materials are related to the length and amount of fiber blended. In the case of small dosage, the toughness performance is mainly related to the length of the blended fiber. When the length of the blended fiber is increased, the toughness is also increased. When the blending amount is large, the toughness property increases with the length of the blended fiber. When increased to a certain extent, the length of the incorporated fiber has little to do with the toughness properties.

\subsection{The influence of the fiber content}

The load-deflection relationship of test pieces with different fiber content for 28 days is shown in Fig. 4.

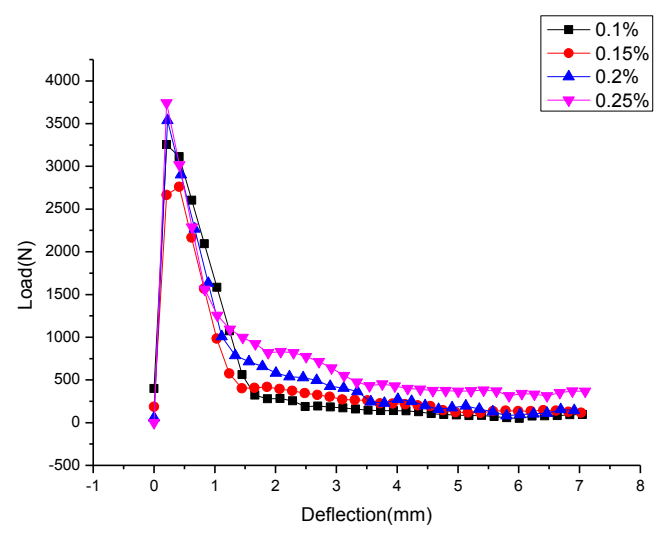

4-1 (28d-10mm)

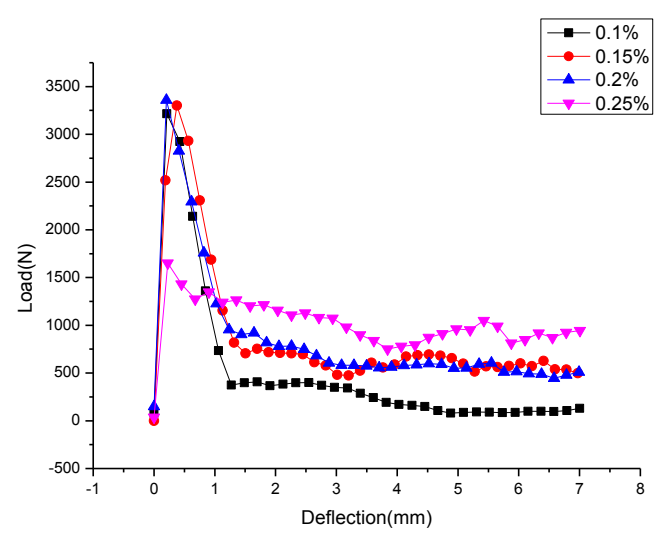

$4-2(28 \mathrm{~d}-15 \mathrm{~mm})$ 


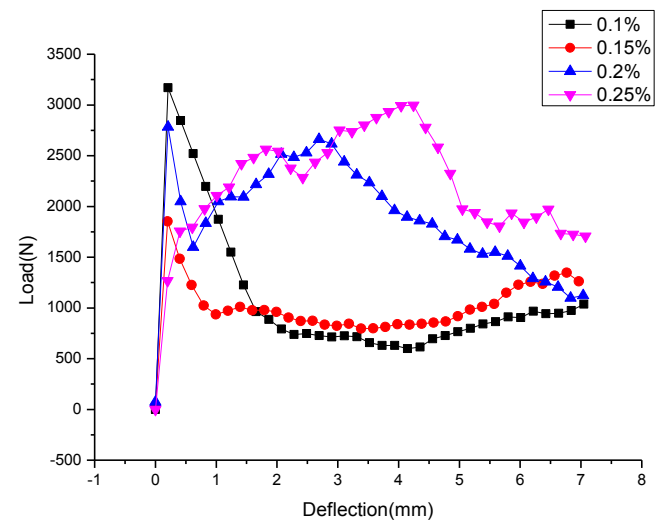

4-3 (28d-20mm)

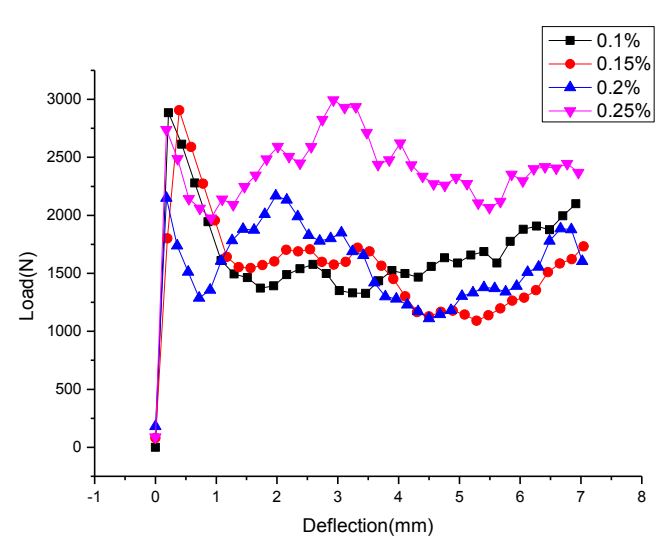

4-4 (28d-25mm)

Fig.4. Relationship between load and deflection curves and the amount of fiber blended

Combined with Figure 4, the following conclusions can be drawn:

(1) When the length of the blended fiber is short, especially when the length of the blended fiber is $10 \mathrm{~mm}$, the residual strength of the test piece doped with different fiber content is all very small, and the flexural toughness is not well improved. However, when the fiber content is increased, the toughness is enhanced.

(2) When the length of the incorporated fiber is long, the flexural strength after the peak is large, and sometimes the flexural strength can approach to the peak. In the post-peak stage, the ductility of a certain load can still increase. The area under the load and deflection curve is larger, and the flexural toughness can be better improved after the peak.

(3) When the fiber length is $20 \mathrm{~mm}$, the residual strength of the test piece with higher dosage is obviously larger than that of the test piece with lower dosage, but the residual strength of the test piece with the dosage of

\section{$0.2 \%$ and $0.25 \%$ is similar.}

(4) When the fiber length is $25 \mathrm{~mm}$ and the amount is larger, the toughness is better, but at a lower dosage, the toughness property has little relationship with the amount.

As summarized in the review, when the length of the blended fiber is short, the toughness property is closely related to the fiber content, and the toughness of the blending amount is also increased. When the length of the incorporated fiber is long, the toughness performance generally increases as the fiber content increases. However, at lower dosages, the toughness properties have little to do with the amount.

\subsection{The influence of the test ages}

Due to the different curing ages of the test pieces, it is varied of the bonding effect between the cement-based material and the fibers. The strength of the cement-based material and the roughness of the fiber-plane contact interface play important roles in the fiber being pulled out of the cement-based material.

Test phenomena and results analysis:

(1) When the test block with the age of 7 days and 28 days is cracked, the bearing capacity of the test block is greatly reduced instantaneously, while for the 3 days old, the peak bearing capacity of the test block appeared after the crack. The reason for this phenomenon may be that the strength of the cement-based material is much smaller than the strength of the abandoned fishing net line when the test piece is 3 days old.

(2) The toughness of the test piece with an age of 28 days was significantly greater than that of the test piece with an age of 3 days. As the age increases, the bond between the cement-based material and the fiber is better. The greater the force required to pull the fibers out of the matrix, the greater the toughness increases.

(3) When the age is short, the strength of the cement-based material is small, the fiber is distributed in the $3 \mathrm{D}$ chaotic direction in the cement-based material, the distribution is not completely uniform, the data obtained by the experiment is more discrete, and the accuracy of the data is lower.

As summarized in the review, the greater the age of the test block, the better the adhesion of the cement-based material to the fiber, the higher the 
toughness, and the better the accuracy of the test.

\section{Discussion on toughening mechanism}

Through careful observation of the anti-folding test process, it is found that after the cracking of the large-scale test block, the bearing capacity of the test block drops instantaneously. However, as the load was continuously loaded, the bearing capacity of the test block arose. When the fiber in the test block was pulled out, a sound was made and the value of the pressure sensor has dropped slightly and then rose again, the process will repeated until most of the fibers were pulled out, and the test piece was almost cracked. During the entire flexural test, the bridging effect of the fiber is obvious. As shown in Fig. 5, it can be observed that many fibers in the cross section of the test piece was pulled out during the test. The test results showed that the load-deflection curve is not a smooth curve. After the peak value, the load size fluctuates continuously. The description of the rise is to overcome the bridging force of the fiber. Once the fiber is pulled out, the bearing capacity will decrease and the crack will continue to expand. When the crack propagation encounters the fiber resistance, the bearing capacity will rise again. Therefore, the relationship between load and deflection reflects the expansion of cracks on the test block to some extent. Therefore, it can be concluded that the randomly distributed fibers in the test block delayed the occurrence and development of cracks. This makes the cement-based fiber toughening material increase the holding deformation process, the breaking property changes from brittle failure to plastic failure. The toughness performance is closely related to the length and dosage of the incorporated fiber. To further reveal the fiber toughening mechanism, this section will analyze the results from the perspective of energy and numerical simulation.

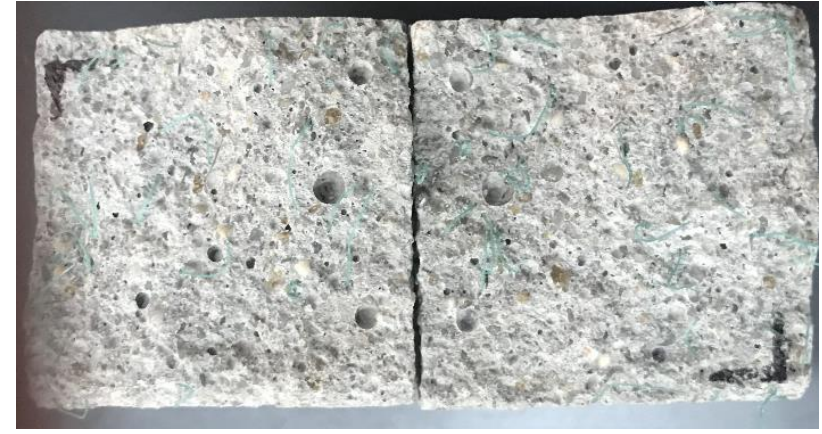

Fig.5. Test piece cross-section fiber pull-out

\subsection{Analyze test results from the aspect of energy}

Since the fiber distribution of most cement-based fiber toughening materials tends to be distributed randomly in different directions ${ }^{[8-11]}$, there is still no perfect method to accurately determine the bending toughness of cement-based fiber toughened materials. Starting from the experimental phenomena and results, the relative area enclosed by the load and deflection curves before the peak load capacity is again greatly reduced, and the failure energy is introduced. The plotted curve is shown in Fig. 6.

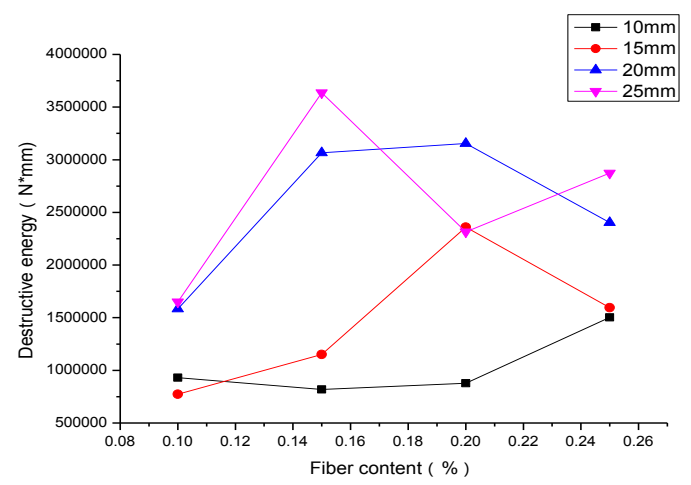

$6-1(3 d)$

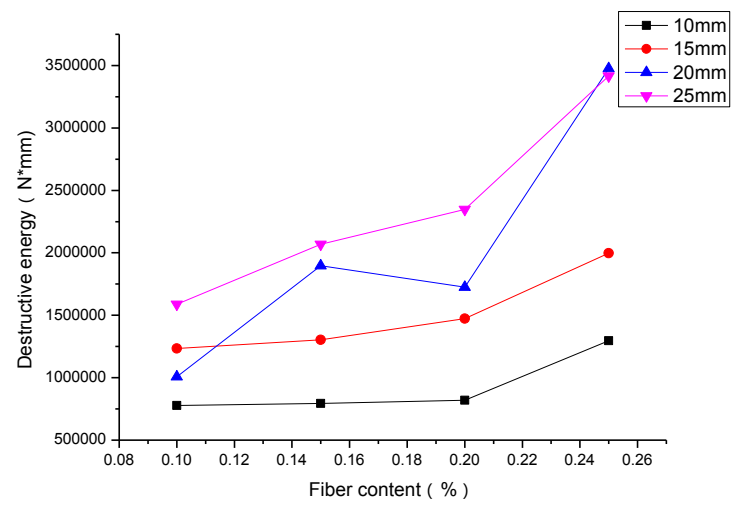

$6-2(7 d)$ 


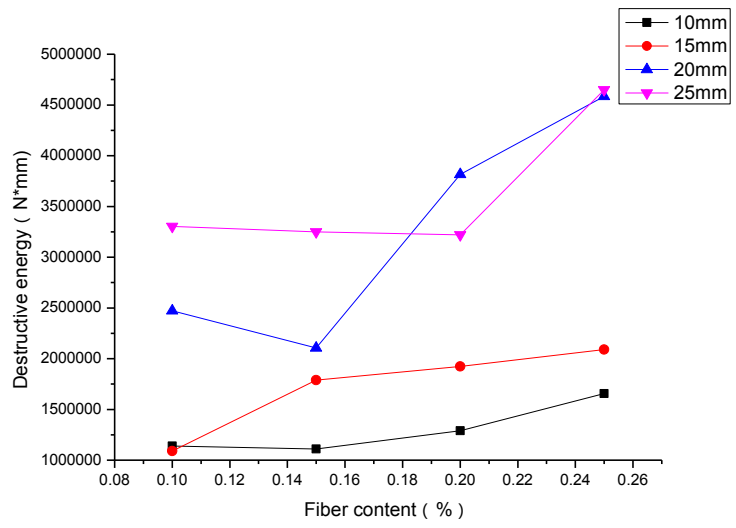

6-3（28d）

Fig.6. Relationship between damage energy size and age, fiber length and dosage

Combining all the graphs, some conclusions can be drawn.

(1) For the test pieces with ages of 7 days and 28 days, the overall trend of the curves obtained by the experiment was similar. When the age of the test block is 3 days, the overall shape of the curve varies. The results of this test are related to the adhesion of the matrix to the fibers.

(2) When the age of the test piece is 7 days and 28 days, as the fiber content and length increase, the area under load and deflection increases, and the toughness also increases.

(3) When the age of the test piece is 7 days and 28 days, and the dosage is $0.25 \%$, the test pieces with fiber lengths of $20 \mathrm{~mm}$ and $25 \mathrm{~mm}$ overcome the similar energy levels.

In summary, the test results are similar to the experimental results. The test procedure of the test piece with the age of 3 days is poor. The fiber content and length increase and the toughness increases. However, when the fiber length and the amount of the fiber are increased to a certain extent, in order to improve the toughness, it is unnecessary to increase the length and the amount as large as possible.

3.2 Analysis of test results from crack width and section pull-out line length

The fibers are distributed in the test block in a chaotic manner. When the crack is expanded, it is necessary to overcome the pinning action of the fiber and the matrix, and consume energy. In the flexural test, the width of the initial crack in the test piece with a period of 28 days was measured and recorded, and the relationship between the length of the blended fiber and the crack width was plotted, as shown in Fig. 7. Then, the length of the fiber pulled out was measured, which exceeded the line length of half of the blending length, and the relationship between the length of fiber and the length of the drawn wire, as shown in Fig.8.

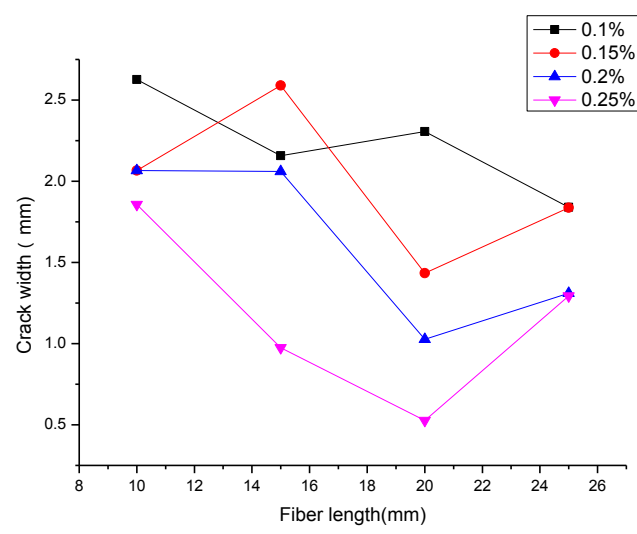

Fig.7.the relationship between fiber length and crack width.

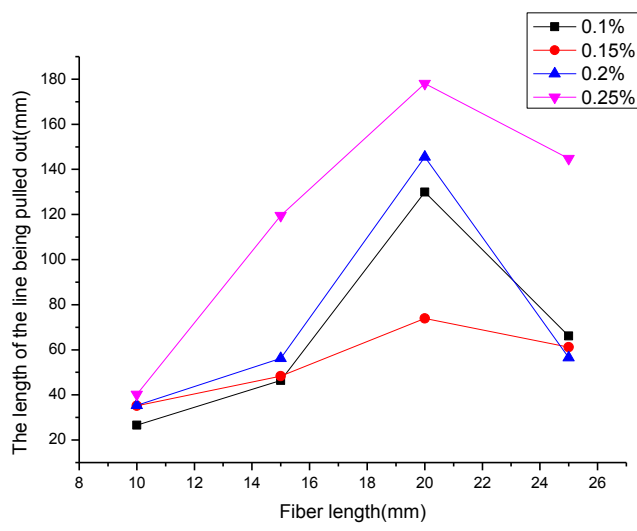

Fig.8. the relationship between the length of fiber and the length of the drawn wire.

Combined with the two relationship diagrams of Figure 7 and Figure 8, the following conclusions can be drawn:

(1)When a large amount of fibers are incorporated in the test piece and the fiber length is $20 \mathrm{~mm}$, the crack width at the time of initial cracking is the smallest, and the line length to be dialed is also the longest.

(2) In general, it can be concluded that the higher the fiber content, the longer the length of the pull-out line and the smaller the crack width at the initial crack.

In summary, the fiber is blended into the cement mortar to prevent cracking. When the fiber length is $20 \mathrm{~mm}$, the crack resistance is the best. 


\subsection{Numerical simulation of the flexural test}

In order to further explain the influence of the blended fiber content on the toughness of the test piece, a four-point bending beam crack propagation model was established, as shown in Fig. 9.

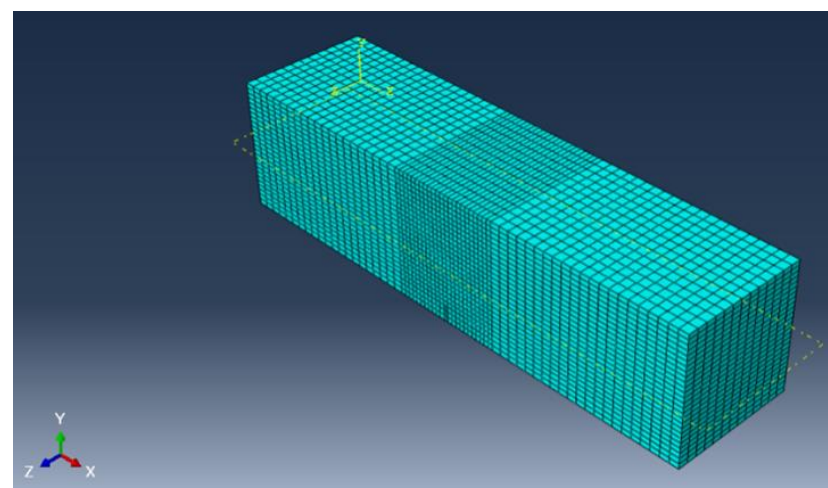

Fig.9. Crack propagation model and mesh division of four-point bending beam

In the numerical simulation, the cement mortar matrix adopts three-dimensional variability solid elements, and the pre-cracking adopts three-dimensional variability shell elements. During the loading process, the crack propagates in the matrix. According to the different amount of fiber blended, the elastic modulus of the model is different. The Poisson's ratio is 0.2 , the mass density is $2400 \mathrm{~kg} / \mathrm{m} 3$, the maximum principal stress is 5450000 , and the damage evolution adopts energy mode. The finite element calculation results show the process of crack propagation, as shown in Figure 10.

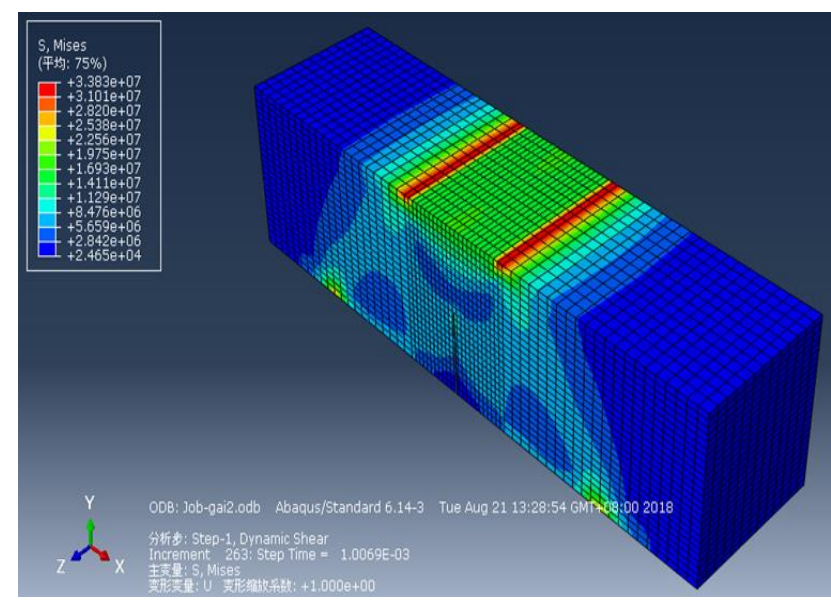

Fig.10. Crack propagation process

According to the volume percentage of the fibers in the matrix, the empirical formula of the surface ${ }^{[12]}$ is used to approximate the elastic modulus of the $3 \mathrm{D}$ chaotic short fiber composite test piece.

$$
\mathrm{E}=1 / 5 E_{f} v_{f}+4 / 5 E_{m} v_{m}
$$

Where $E_{f}$ and $E_{m}$ are the elastic moduli of the fiber and the matrix, $V_{f}$ and $V_{m}$ are the volume fraction of the fiber and the matrix.

According to the different fiber content, four different elastic modulus can be obtained, and the four-point bending beam crack propagation model is established according to different elastic modulus. After the load-deflection curve is obtained by numerical simulation, the relationship between the failure energy and the elastic modulus of the test piece is shown in Fig. 11 from the energy angle analysis. Figure 11 reflects that the modulus of the test piece does not have a very direct effect on the toughness properties of the test piece. Combined with the test results and process, it is shown that the influence of the amount of fiber on the elastic modulus of the test block is not the key to toughening. The effect of the bridging action of the fiber and the matrix on the toughness is very important. The length and the amount of the fiber together affect the bridging effect.

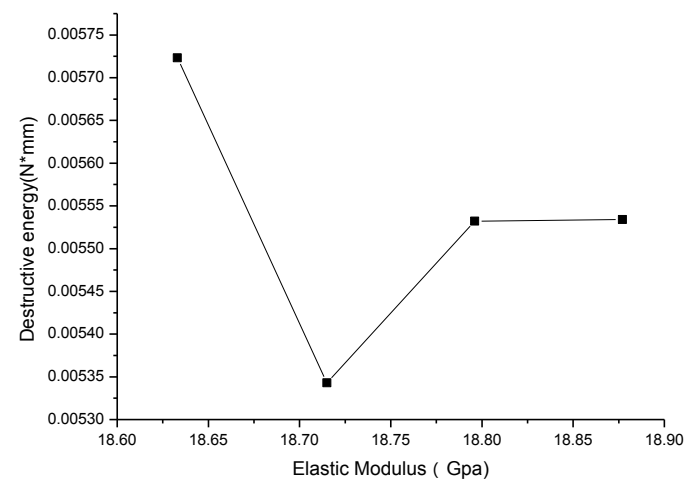

Fig.11. Relationship between failure energy and elastic modulus of test block

\section{Conclusion}

The toughness of the cement-based fiber toughening materials is related to the length and amount of fiber blended, which plays a role of "micro-reinforcing". With the results of the experimental study and numerical simulation, the conclusion are as follows:

(1)In the case of small dosage, the toughness performance is mainly related to the fiber length. When the length of the incorporated fiber increases, the toughness also increases.

(2)When the amount is large, the toughness performance increases when the length of the incorporated fiber 
increases. However, to a certain extent, the length of the incorporated fiber does not influence the toughness properties.

(3) When the length of the incorporated fiber is short, the toughness performance is closely related to the fiber content. When the fiber content is increased, the toughness of the test piece is also increased.

(4) When the incorporated fiber is long, the toughness performance generally increases with the fiber content. However, at lower dosages, the toughness properties are not related to the amount.

(5) The amount and length of the fiber increases, the toughness of the test piece increases. However, when the fiber length and the amount of the fiber are increased to a certain extent, the toughness are not increase with length and the amount of the fiber.

(6) The amount of fiber on the elastic modulus of the test piece is not the key factor of the toughness, but the bridging action of fiber and matrix on the toughness is very important. The length and the amount of fiber affect the bridging effect.

(7) Incorporating fibers into the cement mortar can prevent cracking. The fiber with the length of $20 \mathrm{~mm}$ are most effective.

\section{References}

1. B Barr,P D Newman.Compos.48-53.(1985)

2. $\mathrm{M}$ Elser,E $\mathrm{K}$ Tschegg,S $\mathrm{E} \quad$ Stanzl-Tshegg.J. Compos.Sci.Technol., 56,(1996)

3. V C Li. On J. J. Adv.Concr. Technol., 215-230,(2003)

4. JCI-DFRCC Committee. J. Adv. Concr. Technol, 335-340,(2003)

5. V C Li, G Fischer, Y Kim, Compos.(2003)

6. K Rokogo, T Kanda.HPFRCC. (2005)

7. R G Shen, Q Cui, Q H Li,M.Chin.Bldg. Mater. Ind.(2004)

8. H D Li, S Z Xu. Chin.CE.J.(2010)

9. ASTM C 1018-89 Standard test method for flexural toughness and first2crack strength of fiber reinforced concrete [ $\mathrm{S}]$

10. JSCE-SF4b Method of test for flexural strength and flexural toughness of steel fiber reinforced concrete [ $\mathrm{S}$ ]

11. Z C Deng,P F Zhang, Xue Huiqing,.J BJP

\section{Univ.(2008)}

12. L A Carlsson.Elsevier Sci Pub. Co. (1991) 